\title{
THE VALUE OF QUINIDINE IN THE PREVENTION OF CARDIAC ARRHYTHMIAS AFTER PULMONARY RESECTION*
}

\author{
BY \\ R. L. HURT AND M. BATES \\ From St. Bartholomew's Hospital, London, and the North Middlesex Hospital, London
}

(RECEIVED FOR PUBLICATION NOVEMBER 3, 1957)

A considerable number of patients over the age of 45 years who undergo a lung resection operation develop cardiac arrhythmias during the postoperative period. These arrhythmias may be multiple extrasystoles, atrial fibrillation, or atrial flutter. Multiple extrasystoles do not in themselves influence the cardiac function to any very great extent, but they are often the precursor of the more serious irregularities of atrial flutter and fibrillation.

Atrial fibrillation may present itself clinically in one of two ways. It may cause shock with a severe tachycardia and a large pulse deficit, or it may cause no alteration in the general condition of the patient and be noticed on routine examination. When atrial fibrillation is associated with shock it leads to a deterioration in the general condition of the patient and inability to expectorate bronchial secretions adequately. This state persists until the fibrillation has been controlled by digitalis, which may take as long as $\mathbf{4 8}$ hours.

Although it is rare for atrial fibrillation to cause death following pulmonary resection, it does retard a patient's progress and it is desirable to prevent its occurrence if possible. In the cases reported here, no death was directly attributable to atrial fibrillation, but one patient, who subsequently died from a large pulmonary embolus, had developed acute atrial fibrillation two days after operation, and it is possible that the calf venous thrombosis had developed as a direct result of the peripheral blood stasis during the interval between the onset of atrial fibrillation and its control by digoxin.

The value of quinidine in preventing atrial fibrillation post-operatively has been studied in this investigation. Quinidine was chosen in preference to digitalis because quinidine is mainly depressant in its action whereas digitalis is a

* Presented to the Society of Thoracic Surgeons of Great Britain and Ireland at a meeting in November, 1956. cardiac irritant, and because there is some evidence that digitalis may cause a decrease in the coagulation time of the blood and thus be a factor in the occurrence of post-operative venous thrombosis (de Takats, Trump, and Gilbert, 1944).

\section{MATERIAL}

Three hundred patients submitted to operation have been studied over a period of four years (1952-5). These patients have all been over the age of 45 years, and in almost every one the operation was for bronchial carcinoma. The average age in the whole series was 55 years, and there were 284 men and 16 women. The first 200 patients were operated on by Mr. O. S. Tubbs, Mr. I. M. Hill, and ourselves at St. Bartholomew's Hospital, and the last 100 patients by M. B. at the North Middlesex Hospital.

\section{METHOD}

The patients have been divided into three series, each of 100 consecutive individuals. During the first series the quinidine cover was maintained for five days after operation. Many of these patients developed atrial fibrillation soon after the quinidine had been stopped, and it was realized that the duration of therapy was too short. In the second series the quinidine was given for 10 days, and in this group it was given to alternate patients. In the third series quinidine therapy was given to every patient for 10 days after operation.

All the patients received a test dose of quinidine, grains 3, a few days before operation and none of the 300 reacted adversely to this dose ; but after completion of this investigation, two patients have been noted to be sensitive to quinidine and have developed tachycardia within half an hour of the test dose. In all cases the quinidine was given by mouth.

In the majority of patients the type of cardiac irregularity was confirmed by an electrocardiogram, but in a few normal rhythm had become re-established as a result of therapy before an electrocardiogram could be taken.

In a very few instances, an electrocardiogram showed the cardiac irregularity to be atrial flutter, or 
TABLE I

INCIDENCE OF ATRIAL FIBRILLATION IN CASES OF LUNG RESECTION WITH AND WITHOUT QUINIDINE

\begin{tabular}{|c|c|c|c|c|c|c|c|c|c|c|}
\hline & \multicolumn{3}{|c|}{$\begin{array}{c}\text { First Series } \\
\text { (100 Thoracotomies) }\end{array}$} & \multicolumn{4}{|c|}{$\begin{array}{c}\text { Second Series } \\
\text { (100 Thoracotomies) }\end{array}$} & \multicolumn{3}{|c|}{$\begin{array}{c}\text { Third Series } \\
\text { (100 Resections) }\end{array}$} \\
\hline & $\begin{array}{l}\text { No. of } \\
\text { Cases }\end{array}$ & Regular & $\begin{array}{c}\text { Atrial } \\
\text { Fibrilla- } \\
\text { tion }\end{array}$ & $\begin{array}{l}\text { No. of } \\
\text { Cases }\end{array}$ & Regular & $\mid \begin{array}{c}\text { Atrial } \\
\begin{array}{c}\text { Fibrilla- } \\
\text { tion }\end{array}\end{array}$ & & $\begin{array}{l}\text { No. of } \\
\text { Cases }\end{array}$ & Regular & $\begin{array}{c}\text { Atrial } \\
\text { Fibrilla- } \\
\text { tion }\end{array}$ \\
\hline Extrapericardial pneumonectomy & 21 & 16 & 5 & 39 & 19 & $\begin{array}{l}1 \\
4\end{array}$ & $\begin{array}{l}\text { With quinidine } \\
\text { Without quinidine }\end{array}$ & 37 & 33 & 4 \\
\hline Intrapericardial pneumonectomy & 39 & 25 & 14 & 38 & 14 & $\begin{array}{r}2 \\
10\end{array}$ & With quinidine & 27 & 23 & 4 \\
\hline Lobectomy & 7 & 6 & 1 & 5 & $\begin{array}{r}12 \\
0\end{array}$ & 2 & $\begin{array}{l}\text { With quinidine } \\
\text { Without quinidine }\end{array}$ & 27 & 27 & 0 \\
\hline Inoperable at thoracotomy $\quad$. & 22 & 20 & 2 & 15 & $\begin{array}{l}6 \\
8\end{array}$ & $\begin{array}{l}0 \\
1\end{array}$ & $\begin{array}{l}\text { With quinidine } \\
\text { Without quinidine }\end{array}$ & & & \\
\hline Died within 5 days of operation. . & 11 & & & 3 & & & & 9 & & \\
\hline
\end{tabular}

"flutter-fibrillation." For the purpose of analysis these patients, who were treated by rapid digitalization, are included with those who had atrial fibrillation.

\section{RESULTS}

FIRST SERIES.-In this series of 100 consecutive thoracotomies, quinidine cover was given to every patient. The majority were given grains 3 two days before operation, grains 5 six-hourly one day before operation, and grains 5 six-hourly for the first five days after operation. No patient in this series received quinidine for longer than six days after operation.

The results are shown in Table $I$. A resection was not possible in 22 patients, and, excluding those dying within five days of operation, there were 60 pneumonectomies and seven lobectomies. About one-quarter of the cases of extrapericardial pneumonectomy and one-third of intrapericardial pneumonectomy developed atrial fibrillation. This first series was a pilot investigation, and a large number of patients developed atrial fibrillation within a few days of the cessation of quinidine therapy. It appeared to us that quinidine was of some value in preventing the onset of atrial fibrillation; but the drug had been stopped too soon. It was also thought to be unnecessary to give more than one dose of quinidine before operation.

SECOND SERIES.-In this series of 100 consecutive thoracotomies, alternate patients were given quinidine cover. These people had one pre-opera-

TABLE II

AGE DISTRIBUTION OF PNEUMONECTOMIES IN SECOND SERIES



tive dose of grains 5 , followed post-operatively by grains 5 six-hourly for the first five days, and $\frac{0}{5}$ grains 5 eight-hourly for the next five days.

The results are shown in Tables $I$ and II. $A$ o resection was not possible in 15 cases, and, again $\stackrel{\bar{S}}{\supset}$ excluding patients dying within five days of operation, there were 77 pneumonectomies and five $\mathcal{G}$ lobectomies. Of the 39 who underwent extra-. pericardial pneumonectomy, atrial fibrillation developed in $5 \%$ of those under quinidine cover and in $21 \%$ of those not under quinidine cover. Of the 38 intrapericardial pneumonectomies, atrial fibrillation developed in $12 \%$ under quinidine $\stackrel{\square}{\stackrel{\perp}{\varrho}}$ cover and in $45 \%$ not under quinidine cover.

The age distribution of these patients (Table II) $\frac{\text { 의 }}{3}$ was the same in the two groups, except that in patients over the age of 61 years there were fewer: in the quinidine group.

ThIRD Series.-In this series of 100 consecutive resections, all patients were given a quinidine $\underset{x}{x}$ cover over the period of operation. The dosage $\frac{0}{3}$ was as in the second series.

The results are shown in Table I. Excluding $\frac{0}{2}$ nine patients who died within five days of operation, there were 64 pneumonectomies and 27 음 lobectomies. Atrial fibrillation developed in four $\rightarrow$ out of 37 extrapericardial pneumonectomies $(11 \%)$ 을. and in four out of 27 intrapericardial pneumon- N ectomies $(15 \%)$.

\section{Discussion}

For many years quinidine has been used in the? prevention and termination of cardiac irregulari-e ties. It is usually effective in cases of atrial fibril- $\bar{\varnothing}$ lation, atrial flutter, atrial and ventricular extra-? systoles, and paroxysmal ventricular tachycardia. $\frac{T}{0}$ There are very few contraindications to its use $\frac{0}{\mathbb{D}}$ and the incidence of toxic symptoms is small.

This investigation shows that quinidine is $a \stackrel{\mathbb{D}}{\unrhd}$ valuable drug for preventing post-operative $\overline{0}$ arrhythmias in patients over the age of 45 years. 
This is especially so in those in whom an intrapericardial pneumonectomy has been performed, for without the use of quinidine atrial fibrillation occurs in nearly half of these cases. Even after an extrapericardial pneumonectomy in this age group, atrial fibrillation is likely in about onefifth of the cases. The use of quinidine reduces the incidence of atrial fibrillation by at least onehalf, even, as in the second series, by as much as one-quarter.

In the first series an attempt was made to control those patients who developed atrial fibrillation while still on quinidine therapy by increasing the dose of quinidine to grains 5 two-hourly for six doses, and then returning to the original dosage after a lapse of 24 hours. Many of these patients had to be given digitalis even after this increased dose of quinidine, and therefore in the second and third series all those who developed atrial fibrillation while still on quinidine therapy were given digitalis over a period of 24 hours, and the quinidine discontinued. This procedure was more satisfactory in controlling the ventricular rate and so in reverting the heart to sinus rhythm.

Quinidine toxicity has not been noted and in no case has the subsequent control of the cardiac irregularity with digitalis been made difficult by the previous use of quinidine. It is considered that quinidine is a valuable drug in the prevention of post-operative cardiac irregularities in patients undergoing pulmonary resection who are over the age of 45 years.

The use of quinidine after pulmonary resection has also been suggested by Cerney (1957), who noted a high incidence of arrhythmias after pneumonectomy.

\section{SUMMARY}

An investigation has been made into the value of quinidine in the prevention of post-operative cardiac arrhythmias in patients over the age of 45 years undergoing pulmonary resection.

The 300 patients have been divided into three series, each of 100 consecutive cases. In the first, which was a pilot investigation, quinidine was given to most patients for five days after operation. In the second, quinidine was given for 10 days after operation to alternate patients. In the third series, everybody received quinidine for 10 days after operation.

Forty-five per cent. of patients who were not given quinidine developed atrial fibrillation after intrapericardial resection and $20 \%$ of those who had had an extrapericardial resection. Patients who received quinidine cover developed atrial fibrillation in $15 \%$ and $11 \%$ of cases respectively. In the second series, the proportion of patients developing atrial fibrillation while on quinidine cover was smaller.

No case developed a toxic reaction to quinidine.

It is considered that quinidine is a valuable drug in the prevention of cardiac arrhythmias following lung resection in patients over the age of 45 years.

We should like to thank Mr. O. S. Tubbs and Mr. I. M. Hill for permission to include their patients in this study and for their most valuable advice and encouragement in the preparation of this paper.

\section{REFERENCES}

Cerney, C. I. (1957). J. thorac. Surg., 34, 105.

de Takats, G., Trump, R. A., and Gilbert, N. C. (1944). J. Amer. med. Ass., 125, 840 . 